Jurnal Pendidikan Bahasa dan Sastra Indonesia is licensed under A Creative Commons Attribution-Non Commercial 4.0 International License

\title{
Ragam Fungsi Gestur pada Tuturan Deiksis dalam Film 3 Srikandi: Analisis Multimodal Korpus
}

\author{
Destiani ${ }^{1}$, Andayani $^{2}$, Muhammad Rohmadi $^{3}$ \\ 1. Pascasarjana Fakultas Keguruan dan Ilmu Pendidikan Universitas Sebelas Maret, Surakarta \\ E-mail: destianiku@gmail.com \\ 2. Pascasarjana Fakultas Keguruan dan Ilmu Pendidikan Universitas Sebelas Maret, Surakarta \\ E-mail:bu_anda09@yahoo.co.id \\ 3. Pascasarjana Fakultas Keguruan dan Ilmu Pendidikan Universitas Sebelas Maret, Surakarta \\ E-mail: mamad_r76@staf.uns.ac.id
}

\begin{abstract}
Abstrak. Bahasa Indonesia beberapa tahun terakhir ini makin banyak dipelajari oleh berbagai negara. Pembelajaran Bahasa Indonesia bagi Penutur Asing (BIPA) memerlukan multimedia untuk menunjang unsur gestur pada materi deiksis. Penelitian ini bertujuan mendeskripsikan keragaman fungsi gestur pada tuturan deiksis dalam Film 3 Srikandi. Teknik pengambilan sampel dengan purposive sampling dengan data penelitian melputi unsur verbal dan nonverbal. Data verbal berupa deiksis, sedangkan unsur nonverbal berupa berbagai gestur yang hadir saat tokoh mengucapkan deiksis. Pengumpulan data menggunakan teknik simak dan catat. Sementara itu, data diolah dengan menggunakan analisis isi dengan pendekatan multimodal. Hasil penelitian menunjukkan tuturan deiksis yang disampaikan para tokoh dapat menampilkan beberapa gestur sehingga fungsi gestur pun beragam. Penggunaan multimedia Film 3 Srikandi membantu proses pembelajaran deiksis dengan adanya unsur nonverbal yang melekat pada dialog tokoh. Pengajar BIPA dapat menggunakan film sebagai media pembelajaran yang membantu untuk menjelaskan materi deiksis. Selain itu, multimedia dapat menstimulus mahasiswa dalam berkomunikasi serta memperbanyak kosakata baru yang diperoleh di kelas bahasa.
\end{abstract}

Kata kunci : bahasa Indonesia; deiksis; gestur; mahasiswa asing; multimedia

\section{PENDAHULUAN}

Akhir-akhir ini bahasa Indonesia diminati banyak negara untahasa Indonesia saat ini, seperti Amerika, Kanadauk dipelajari. Ada 45 negara yang mengajarkan b, Australia, Vietnam, dan negara lainnya. Bahasa ini pun menjadi bahasa populer ke4 di Australia. Bahkan, para siswa di Australia mampu berbahasa Indonesia (Andayani, 2015). Sepertinya misi pengajaran Bahasa Indonesia bagi Penutur Asing (BIPA) untuk menginternasionalisasikan bahasa Indonesia memberikan kabar gembira. Tak sedikit mahasiswa asing mengikuti program Beasiswa Darmasiswa untuk memperoleh program BIPA di kampuskampus Indonesia.

Unit Pelaksana Teknis (UPT) Bahasa merupakan wadah program BIPA di Universitas Sebelas Maret (UNS). Mahasiswa yang bergabung di program ini diharuskan mampu berbahasa Indonesia (Kusmiatun, 2016: 1). Dalam proses pembelajaran, pengajar tak terlepas dari buku teks. Buku teks acapkali dijadikan kunci dalam pemerolehan bahasa target mahasiswa. Seperti yang disampaikan Skolverket (2006) sebanyak 75\% pengajar mengandalkan buku ajar di kelas bahasa. Artinya, buku ajar memang memegang peranan penting antara komunikasi pengajar dengan mahasiswanya sebab berisikan instrumen pembelajaran materi (Richards, 2001; Cunningsworth, 1995).

Buku ajar BIPA Sahabatku Indonesia yang digunakan UPT UNS menyajikan berbagai materi sebagai masukan bahasa. Berbagai kosakata dan gramatikal menjadi garda terdepan proses pembelajaran. Kegramatilan bahasa yang baik dapat menciptakan komunikasi yang baik pula. Piranti kohesi adalah cara menempuh kegramatikalan bahasa (Tanskanen, 2006). Piranti tersebut mengacu 
pada fitur linguistik yang menghasilkan jalinan kalimat menjadi padu dan berterima (Alarcon dan Morales, 2011).

Deiksis merupakan rujukan benda yang letaknya dekat ataupun jauh dari sumber pembicara (Hanks, 2009). Intinya, bergantung di mana keberadaan pembicara. Levinson (1983) dan Green (2015) menyatakan deiksis ialah bagian piranti kohesi digunakan sebagai penanda dari kondisi lokasi yang bersifat tidak tetap. Deiksis berfungsi menghubungkan bahasa dengan konteks dan jika seseorang memahami deiksis dengan baik maka baik juga pemahamannya terhadap konteks (Prasch, 2016). Lebih jelas lagi, Putrayasa (2014) menyatakan bentuk bahasa bersifat deiksis apabila acuannya tidak tetap bergantung pada pembicara dan tempat dituturkannya kata-kata tersebut. Berdasarkan pendapat para pakar di atas, sintesis dari deiksis ialah sebuah kata atau lebih yang merujuk pada bagian dari bahasa dan konteks yang bergantung pada waktu, jarak, dan pembicara/ penulis berada.

Deiksis dibagi menjadi tiga jenis, yakni pembicara/ penulis (orang), waktu ujaran (waktu), dan lokasi (ruang). Contoh dari masing-masing bentuk ialah kata ganti orang (saya, Anda), demonstratif (ini, itu), dan keterangan waktu atau tempat (sekarang, di sini, di situ) (Mulderrig, 2012). Dalam konteks tatap muka, ujaran pembicara mudah dimengerti oleh lawan bicara sebab rujukan dapat dijelaskan secara langsung (O`Keefe et al., 2011). Kesulitan mahasiswa menggunakan deiksis dapat dikarenakan deiksis diajarkan secara verbal. Komunikasi akan efektif jika unsur verbal dan nonverbal dijarkan keduanya. Unsur verbal meliputi bahasa secara tertulis dan lisan, sedangkan nonverbal berupa gestur, ekspresi wajah, intonasi suara, dan sebagainya. Penggunaan unsur verbal dan nonverbal akan memudahkan seseorang menyampaikan pesan (Bonsignori, 2018). Akan tetapi, materi deiksis disajikan secara verbal dalam buku ajar BIPA Sahabatku Indonesia, padahal studi sebelumnya data korpus AntConc menunjukkan penggunaaan deiksis jumlah cukup tinggi. Peneliti seperti Franceschi (2018) menjelaskan buku ajar banyak berfokus pada unsur verbal sehingga tidak mengindahkan nonverbal yang dibutuhkan mahasiswa dalam pemerolehan bahasa.

Multimedia kini menjadi sarana yang menunjang proses belajar. Banyak bentuk multimedia yang dapat digunakan pengajar seperti contohnya video. Video merupakan media untuk meningkatkan kretivitas sebab mampu menghadirkan obyek sebenanrnya melalui gerak gambar dan suara (Rahmawati, Santoso, dan Andajani, 2017). Peneliti seperti Lei (2016) merasakan para siswa terstimulus minat belajarnya di kelas bahasa asing saat menggunakan video.
Unsur-unsur wacana nonlinguisitk pada video memberikan pembelajaran yang sangat signifikan (Harmer, 2007: 308). Video pembelajaran memungkinan dapat menjaga relevansi antara materi dengan tujuan tujuan pembelajaran yang hendak diraih.

Unsur nonverbal seperti gestur, eskpresi, dan intonasi penutur memberikan fungsi terhadap pesan apa yang hendak disampaikan. Seorang pakar bernama Kendon (2004) membagi fungsi gestur ke dalam beberapa bagian meliputi deiktik (posisi tangan atau kepala menunjuk pada objek rujukan di dekat lokasi penutur atau menunjuk interlokutor); representasional (gestur tangan atau wajah mempresentasikan objek bersifat abstrak); performatif (gerakan tangan atau wajah dengan cara menggeleng untuk menjawab tidak); framing (gestur mucul saat menjelaskan atau menceritakan disertai rasa emosi); diskursif (gestur untuk menekankan aspek linguistik tertentu); interaktif (gestur dengan tatapan mata ke lawan bicara, pembicara meminta agar interlokutor memerhatikannya); dan mencari kata (gestur tangan atau ekspresi wajah yang mengindikasikan pembicara mencari-cari kata).

Film 3 Srikandi merupakan film pembelajaran yang menceritakan tiga atlet panahan yang meraih medali dalam ajang Olimpiade Musim Panas 1988 di Seoul, Korea Selatan. Film yang ditayangkan pada pertengahan 2016 sengaja dihadirkan untuk mengenang sejarah kemenangan Indonesia. Film tersebut diperankan oleh Reza Rahardian, Bunga Citra Lestrari, Chelsea Islan, dan Tara Basro ini meraih Piala Citra Indonesia (Nohara dan Brotoseno, 2016). Berbagai penghargaan diraih para pemain, Film 3 Srikandi cocok dijadikan media pembelajaran nonverbal pada tuturan deiksis bahasa Indonesia. Dengan menggunaan film sangat memungkinkan mahasiswa terlibat aktif dalam pembelajaran (Parker \& Faulk, 2004; Toman \& Rak, 2000). Berdasarkan uraian di atas, perumusan masalah dalam penelitian ini ialah bagaimana fungsi gestur pada tuturan deiksis ini dan itu dalam film 3 Srikandi?

\section{METODE}

Penelitian ini berjenis kualitatif dengan pendekatan multimodal korpus. Multimodal ialah pendekatan analisis wacana yang memiliki beragam material yang dapat dianalisis, seperti gerakan, ucapan, gambar (diam atau bergerak), tulisan, musik, ataupun film yang terdapat dalam website (Kress, 2011). Dalam hal ini, subyek penelitian ialah Film 3 Srikandi. Film 3 Srikandi merupakan film Indonesia yang menceritakan kisah perjuangan tiga atlet wanita panahan yang berhasil meraih medali di kancah internasional. Film ini mendapatkan penghargaan Piala Citra 2016 dan menduduki rating 
memuaskan. Film tersebut dibintangi empat pemeran utama terdiri atas Reza Rahardian sebagai Donald Pandiangan, Bunga Citra Lestari sebagai Nurfitriyana Saiman, Chelsea Islan sebagai Lilies Handayani, dan Tara Basro sebagai Kusuma Wardhani (Media, 2016).

Sementara itu, obyek dari penelitian ialah unsur verbal dan nonverbal. Unsur verbal meliputi deiksis ini dan itu, sedangkan unsur nonverbal meliputi gerak tubuh, ekspresi, dan intonasi dalam film 3 Srikandi. Pada studi sebelumnya, deiksis ini dan itu pada buku ajar Sahabatku Indonesia diketahui melalui data korpus AntConc 3.4.5 dan berjumlah 309 buah. AntCon 3.4.5 adalah software yang dapat mengetahui seberapa banyak frekuensi sebuah kata digunakan dalam sebuah tulisan dan tuturan (Anthony, 2014). Jadi, jumlah deksis ini dan itu dapat dengan mudah diketahui jumlahnya dalam buku.

Penelitian ini mengambil sampel dari kutipankutipan adegan film dengan cara purposive sampling. Purposive sampling adalah proses pengumpulan data dengan berbagai pertimbangan tertentu untuk mendapatkan data represntatif (Sugiyono, 2017: 85). Adapun teknik pengumpulan data memnggunakan simak dan catat. Simak adalah teknik yang digunakan untuk memperoleh data dengan menyimak suara atau melihat dari video, sedangkan catat adalah teknik mencatat bagian mana saja yang hendak dianalisis (Mahsun, 2007: 29). Langkah-langkah pengumpulan data sebagai berikut. Pertama, pengunduhan film dari https://indoxx1.com/movie/download-film-3srikandi-full-movie-1satt/play. Kedua, menonton film dan mengidentifikasi unsur verbal dan nonverbal dengan menggunakan teknik simak dan catat. Analisis data dilakukan dengan teknik analisis isi dengan pendekatan multimodal. Analisis isi yaitu membuat kesimpulan dengan cara mengidentifikasi karakteristik-karakteristik data tertentu secara obyektif dan sistematis dengan prosedur tertentu (Holsti, 1969: 28). Setelah data terkumpul, langkahlangkah peneliti menganalisis data meliputi (a) mencatat deiksis ini dan itu merujuk pada objek riil atau abstrak; (b) mencatat konteks sesuai dengan adegan dan dialog para tokoh; (c) mengidentifikasi dan mencatat fungsi gestur yang dilakukan tokoh saat menuturkan deiksis ini dan itu; (d) mengidentifikasi dan mencatat hubungan antara gestur dan tuturan pada deiksis ini dan itu, (e) menyimpulkan berdasarkan variasi fungsi dan hubungan gestur dengan tuturan deiksis ini dan itu.

\section{HASIL DAN PEMBAHASAN}

Gestur pada tuturan deiksis ini dan itu beragam dalam film 3 Srikandi. Deiksis-deiksis tersebut mengacu pada rujukan benda yang bersifat konkret dan abstrak sesuai dengan konteks situasi tuturan yang disampaikan. Kemudian, fungsi gestur yang terdapat pada tuturan deiksis pun beragam meliputi deiktik, representasional, framing, diskursif, dan interaktif. Berikut ini analisis data penelitian.

\section{a. Tuturan Deiksis ini}

Data yang diperoleh dari Film 3 Srikandi terdapat penggunaan deiksis itu. Berikut ini pemaparan analisis ragam gestur pada tuturan deiksis itu.

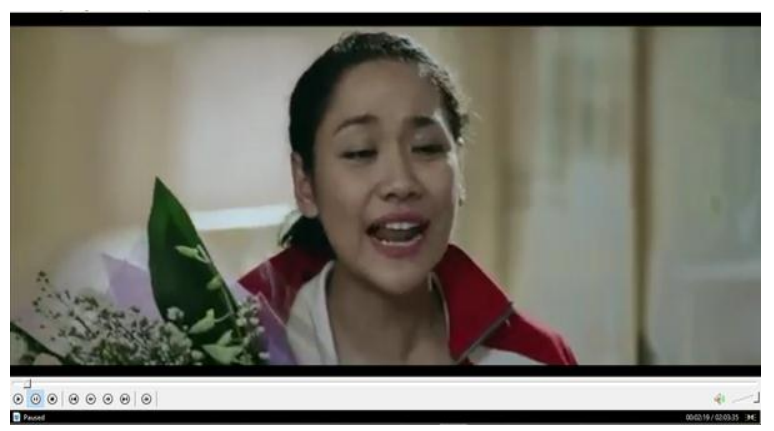

Gambar 1: Yana heran dengan sikap bapak

Konteks dalam adegan berlangsung antara Nurfitriyana (Yana), ibu, dan bapak. Tokoh Yana baru tiba di rumah setelah memenangkan SEA Games XIV tahun 1987. Yana pulang membawa medali dan karangan bunga yang hendak ia tunjukkan pada kedua orangtuanya, khususnya bapak. Akan tetapi, ketika tiba di rumah, sang bapak tidak memedulikan sehingga Yana kecewa. Yana pun menanyakan mengapa bapaknya bersikap demikian. Kemudian, bapak marah besar karena Yana menyibukkan dirinya di kompetisi panahan. Bapak Yana ingin putrinya fokus dengan studinya di strata 1. Berikut ini kutipan dialog antara Yana, ibu, dan ayah Yana.

\begin{tabular}{|c|c|}
\hline Yana & $\begin{array}{l}\text { "Bu, Ibu." (nada bahagia, } \\
\text { girang, dan tersenyum) }\end{array}$ \\
\hline Ibu & $\begin{array}{l}\text { :"Selamat ya, Yana." } \\
\text { (bahagia) }\end{array}$ \\
\hline Yana & $\begin{array}{l}\text { : "Bapak mana? Yana mau } \\
\text { kasih ini." (mencari } \\
\text { keberadaan bapak) }\end{array}$ \\
\hline Bapak & $\begin{array}{l}\text { "Matikan lampu itu! } \\
\text { Malam-malam bikin } \\
\text { ramai!" (berada di } \\
\text { ruang tengah) }\end{array}$ \\
\hline Yana & $\begin{array}{l}\text { :"Pak, Yana menang, Pak." } \\
\text { (bahagia, menunjukkan } \\
\text { medali dan bunga) }\end{array}$ \\
\hline Bapak & $\begin{array}{l}\text { :"Lalu Bapak mesti } \\
\text { ngapain? } \\
\text { Loncat-loncat kegirangan? }\end{array}$ \\
\hline
\end{tabular}




$$
\begin{aligned}
& \text { (menatap dan ekspresi } \\
& \text { marah) : "Sudahlah, Pak, jangan } \\
& \text { terlalu } \\
& \text { keras." (menenangkan) } \\
& \text { Yana : "Bapak kok ngomongnya } \\
& \text { gitu } \\
& \text { sih? Ini kan jalan Yana } \\
& \text { menuju olympiade." } \\
& \text { (memasang wajah heran) } \\
& \text { Bapak : "Cukup." (nada meninggi } \\
& \text { dan marah) }
\end{aligned}
$$

Dialog di atas terdapat deiksis ini pada kutipan kalimat Ini kan jalan Yana menuju olimpiade. Ketika Yana mengucapkan deiksis ini, intonasinya meninggi, serta ekspresinya menunjukkan rasa heran karena sang bapak tidak suka atas kemenangannya di SEA Games. Pandangan mata Yana tertuju pada bapak. Kata ini merujuk pada kemenangan yang diraih Yana dan rujukan tersebut bersifat abstrak. Gestur-gestur yang ditunjukkan Yana menyatakan fungsi gestur sebagai representatif, framing, dan interaktif karena obyek rujukan yang dimaksud bersifat abstrak, ekspresi dan gerak yang mucul saat menjelaskan suatu hal, serta tatapan mata kepada lawan bicara secara langsung. Deiksis ini disampaikan pada waktu 00:02:19.

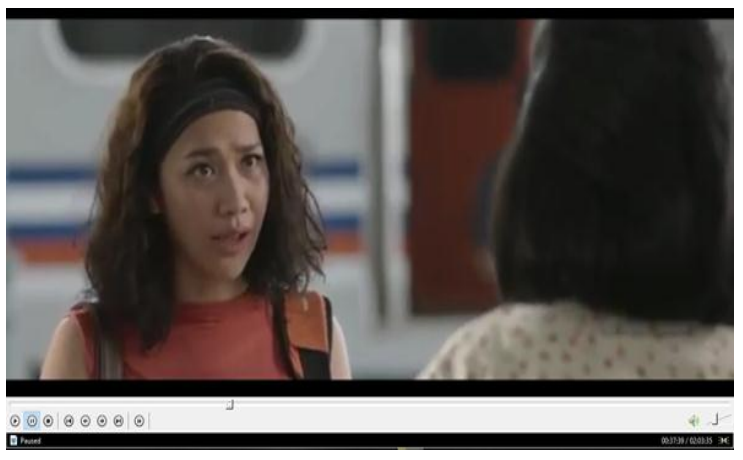

Gambar 2. Yana menjelaskan karena pergi tanpa pamit

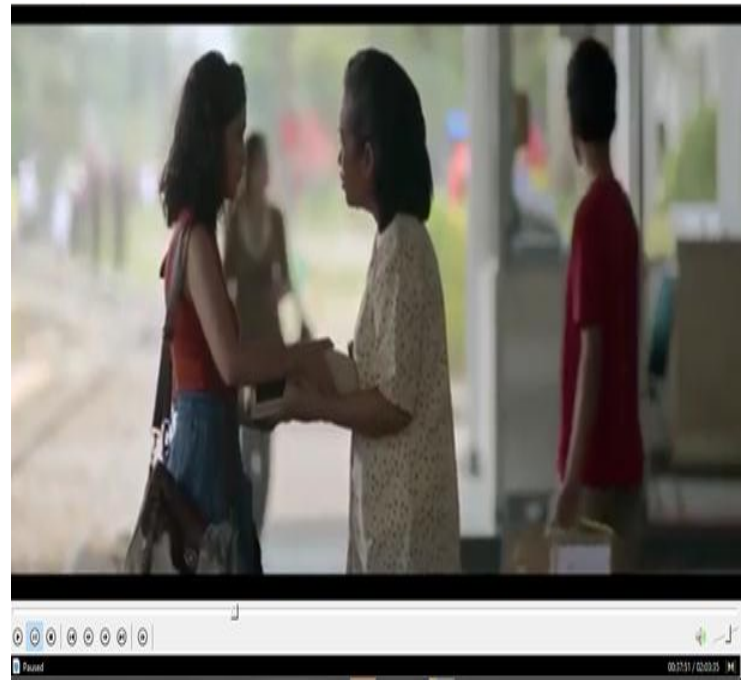

Gambar 3. Ibu memberikan mesin tik

Kedua gambar di atas berlangsung hampir dalam satu waktu bersamaan. Konteks gambar pertama ketika Yana pergi tanpa pamit untuk mengikuti Pelatnas di Sukabumi. Sebelum kepergiannya, ibunya Yana datang ke stasiun kereta bersama pesuruhnya. Ia menanyakan mengapa Yana pergi tanpa pamit pada kedua orangtuanya. Tokoh Yana ditampilkan dengan rasa kecewa sebab sang ayah belum juga merestui keinginannya untuk bertanding di olimpiade. Ibu Yana berusaha memberikan pengertian kepada Yana bahwa semua itu terjadi karena kekecewaan masa lalu yang diperoleh ayah Yana di tempat kerjanya. Berikut ini kutipan dialog antara ibu dan Yana di stasiun.

Ibu : "Kenapa kamu pergi tanpa pamit? Masih marah sama bapak? Yana, kamu kan tahu,

bapak pensiun dengan banyak

kekecewaannya di

kesatuannya. Jadi dia

melimpahkan

kemarahannya

pada keluarganya

sendiri."

(sedih)

Yana : "Yana cuma nggak ingin emosi saja menanggapi sikapnya bapak, Bu. Yana harus fokus untuk pelatnas

olimpiade. Ibu tahu kan, olimpiade ini penting buat Yana. (sabar tidak ingin marah)

Lilis : "Mbak, cepet, Mbak!." (di kereta memanggil Yana). Yana 
dan ibu menoleh ke kereta.

"Ini mesin ketiknya.

Jangan lupa menyelesaikan

skripsimu ya."

(menyerahkan mesin tik).

"Hati-hati, Nak." (sambil menepuk-nepuk pelan bahu Yana)

Lilis, Suma : "Mbak Yana, ayo!"

(memanggil lagi dari

kereta lalu Yana menuju

kereta)

Pada dialog di atas terdapat dua penggunaan deiksis ini. Pertama, deiksis ini dalam kutipan Ibu tahu kan, olimpiade ini penting buat Yana. Deiksis ini mengacu pada pertandingan panahan yang akan digelar beberapa bulan kemudian. Rujukan dari deiksis tersebut bersifat abstrak. Ketika Yana menuturkan kalimat tersebut terlihat tatapan matanya tertuju pada lawan bicara (ibu), lalu ekspresi dan intonasi yang disampaikan Yana berusaha meyakinkan pada ibu bahwa ia serius dan menjadikan olimpiade amat penting dalam perjalanan hidupnya. Yana menginginkan ibu dan bapaknya paham terhadap apa yang dipilihnya saat ini. Berdasarkan dialog Yana, gestur dalam kutipan berfungsi sebagai representasional, performatif, dan framing sebab rujukan deiksis bersifat abstrak serta tokoh menginginkan lawan bicaranya mengerti apa yang diinginkan dan berusaha meyakinkan bahwa ia sangat serius olahraga di bidang panahan.

Kedua, tokoh ibu menyampaikan deiksis ini dalam dialog Ini mesin ketiknya. Deiksis ini mengacu pada benda/ obyek riil berupa mesin tik yang dalam hal itu tokoh ibu menyerahkan benda tersebut langsung oleh Yana. Kemudian, saat ibu menyerahkan mesin tik tersebut, terdapat juga beberapa kali anggukan yang dirujukkan pada mesin tik. Suara ibu melembut dengan harapan Yana menerima pemberiannya dan mau mengerjakan tugas akhir kuliahnya. Kemudian, tatapan mata ibu tertuju pada Yana. Berdasarkan unsur-unsur tersebut maka fungsi gestur sebagai deiktik. Tuturan deiksis ini berlangsung pada 00:37:50.

\section{b. Tuturan Deiksis itu}

Pada Film 3 Srikandi selain terdapat tuturan deiksis ini, deiksis itu pun digunakan. Berikut ini analisis data ragam gestur yang digunakan saat tuturan deiksis itu diucapkan pemain film.

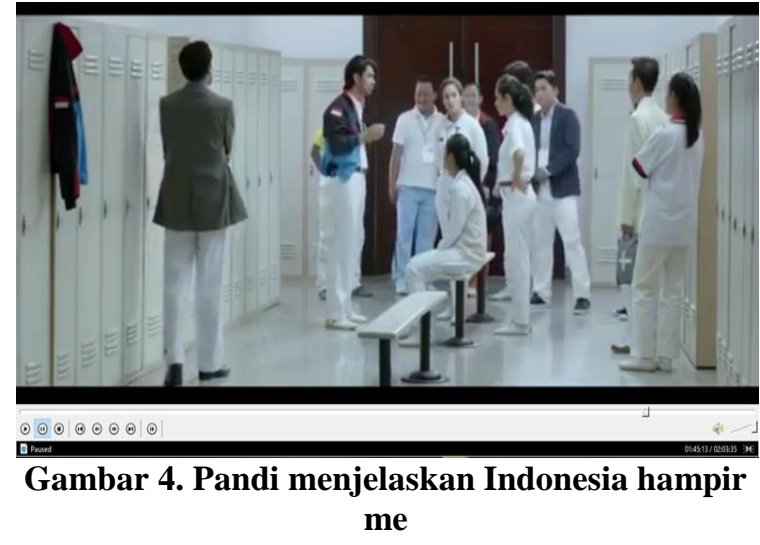

Pada gambar di atas menunjukkan situasi di mana Pandi sedang mengumpulkan tim atlet panahan dan lainnya untuk menyemangatkan kembali tim putri sebab mereka sudah masuk 24 besar. Semuanya berkumpul di saat dua jam lagi pertandingan dimulai. Pandi berdiri di hadapan banyak orang untuk menguatkan bahwa kemenangan Indonesia untuk meraih medali sebentar lagi. Berikut ini kutipan dialog dalam film.

Pandi : "Coba dengarkan! Dalam dua jam ke depan akan menjadi wakil yang sangat menentukan untuk kalian.

Kalian sudah sedekat itu untuk meraih kemenangan. Buat Abang, tidak ada yang namanya hampir menang. Yang ada hanyalah menang $\mathrm{d}$ kalah."

(nada tegas dan tatapan ditujukan ketiga atlet)

Yana $\quad$ :... (mengangguk)

Penggunaan deiksi itu terdapat dalam kutipan dialog Kalian sudah sedekat itu untuk meraih kemenangan yang disampaikan Pandi sebagai pelatih tim putri. Deiksis itu merujuk pada waktu kemenangan untuk meraih medali. Rujukan tersebut bersifat abstrak. Pada gambar juga, terlihat ekspresi Pandi yang sangat serius akan kemenangan Indonesia. Kemudian, posisi tangan naik dan bergerak-gerak setiap kalimat-kalimat penegasan yang disampaikannya sambil mengangguk-angguk mengikuti gerakan tangan. Tidak hanya itu, pandangannya matanya berfokus pada tiga atlet yaitu Yana, Suma, dan Lilis. Ia secara tidak langsung meyakinkan pada tim bahwa Indonesia akan menang. Berdasarkan penjelasan, fungsi gestur yang terdapat dalam tuturan deiksis tersebut sebagai representasional, framing, dan interaktif. Deiksis itu dituturkan pada waktu 01:45:13. 


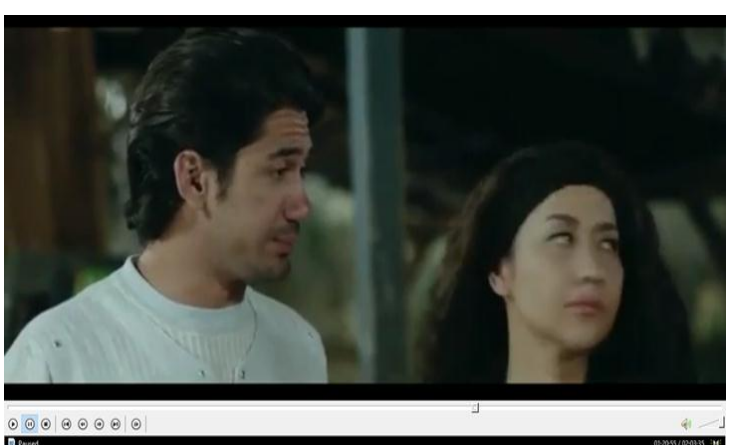

Gambar 5. Pandi menjelaskan rakyat ingin atlet Indonesia menang

Pada gambar menunjukkan kondisi Pandi, Yana, Suma, dan Lilis sedang menonton pertandingan bulutangkis bersama rakyat. Kemudian, Indonesia kalah skor dengan lawannya dan rakyat mengomentari permainan bulutangkis yang tidak bagus asal Indonesia. Pandi kemudian bangun dari duduk dan menjauh. Tak lama ia memanggil Yana, Suma, dan Lilis. Berikut ini dialog yang disampaikan Pandi.

\begin{tabular}{|c|c|}
\hline Pandi & $\begin{array}{l}\text { : "Kalian lihat itu mereka } \\
\text { tuh? } \\
\text { Mereka itu rakyat yang } \\
\text { membiayai kita." } \\
\text { (pandangan Yana ke } \\
\text { rakyat yang sedang } \\
\text { menonton } \\
\text { pertandingan } \\
\text { bulutangkis). } \\
\text { "Membiayai latihan } \\
\text { semua } \\
\text { keperluan kalian. Mau } \\
\text { mengecewakan } \\
\text { mereka?" }\end{array}$ \\
\hline Yana & : “...” (geleng-geleng) \\
\hline Pandi & $\begin{array}{l}\text { :"Kalau begitu raih } \\
\text { kesempatan yang ada. }\end{array}$ \\
\hline Buat & $\begin{array}{l}\text { Indonesia bangga." (lalu } \\
\text { pergi meninggalkan }\end{array}$ \\
\hline & Suma, dan Lilis) \\
\hline
\end{tabular}

Pada dialog terdapat penggunaan deiksis itu dalam kutipan kalimat Kalian lihat itu mereka tuh? Mereka itu rakyat yang membiayai kita. Deikisi itu pada kalimat-kalimat tersebut merujuk pada rakyat yang menonton pertandingan bulutangkis. Obyek rujukan yang disampaikan Pandi bersifat konkret. Kemudian, tatapan mata Pandi pada lawan bicaranya, yaitu Suma, sedangkan Suma langsung menoleh ke arah rakyat yang sedang menonton. Konteks dalam dialog, Pandi menekankan agar tim regu yang dilatihnya tidak mengecewakan rakyat dan nama Indonesia. Dengan penjelasan yang disampaikan Pandi, Yana mengangguk sebagai jawaban paham atas pernyataan Pandi. Berdasarkan uraian tersebut, maka fungsi gestur sesuai dengan tuturan deiksis itu ialah deiktik, framing, diskursif, dan inetarktif. Deiksis itu dituturkan pada 01:20:55.

Hasil penelitian menunjukkan penggunaan multimedia dalam materi deiksis diperlukan mahasiswa di kelas bahasa. Selain menumbuhkan rasa minat belajar, materi ini akan lebih mudah dipahami jika disandingkan dengan media yang sesuai seperti film. Hal ini sesuai dengan pendapat Hanks (2009) menyatakan bahwa deiksis ini dan itu dapat digunakan secara luas dan dapat menimbulkan kebingungan bagi orang yang menerima pesan dalam berkomunikasi. Hank menyarankan untuk memahami deiksis sebaiknya dipelajari konteks dan pragmatiknya agar terhindar dari kesalahpahaman. Unsur mempelajari konteks dan pragmatik dapat diperoleh melalui media pembelajaran film sebab menyajikan unsur verbal dan nonverbal. Kemudian, penggunaan multimedia sangat tepat dalam pembelajaran deiksis sebab akan mendorong pembelajaran yang bermakna melalui pemahaman yang lebih baik tentang bagaimana memproses informasi yang disampaian penutur (Holder \& Young, 2010). Dengan penggunaan multimedia dapat dipastikan kekeliruan dan kesalahpahaman penggunaan deiksi akan terhindar di kelas bahasa asing.

\section{SIMPULAN DAN SARAN}

Deiksis ini dan itu merupakan bagian penting yang menghasilkan kegramatikalan bahasa. Unsur verbal akan lebih mudah dipahami jika unsur nonverbal terlibat di dalamnya. Penggunaan media yang sesuai dalam pengajaran deiksis harus diperhitungkan oleh pengajar. Multimedia dapat dijadikan media pembelajaran yang sesuai untuk pembelajaran deiksis ini dan itu. Melalui ketepatan pemilihan media belajar, unsur nonverbal dan verbal dapat dipahami dengan baik. fungsi gestur dalam film 3 Srikandi beragam meliputi deiktik, representasional, framing, diskursif, dan interaktif. Dengan mengetahui fungsi-fungsi gestur, mahasiswa asing akan tahu bagaimana eskpresi, gerak tubuh, tatapan, dan suara saat mengucapkan deiksis ini dan $i t u$. Pengajar BIPA dapat menggunaan multimedia sebagai media yang efektif dan komunikatif dalam pembelajaran kosakata selain deiksis. Dengan demikian, tidak menutup kemungkinan mahasiswa asing kian bertambah jumlah kosakata yang dimiliki.

\section{DAFTAR PUSTAKA}

Alarcon, J. B., \& Morales, K. N. (2011). Grammatical cohesion in students' 
argumentative essay. Journal of English and Literature, 2, 114-127.

Andayani, P., Pd, M., Gilang, L., \& Sn, S. (2015). The Effectiveness of Integrative Learning Based Textbook toward the Local Culture Comprehension and Indonesian Language Skill of Foreign Students. International Journal of Humanities and Social Science, 5(10), 197-207

Anthony, L. (2014). AntConc (Version 3.4.3) [Computer software]. Tokyo, Japan: Waseda University.

Bonsignori, V. (2018). Using films and TV series for ESP teaching: A multimodal perspective. System, (2015).

Cunningsworth. (1995). Choosing your coursebook. Great Britain: The bath Press.

Francesconi, S. (2014). Reading tourism texts: A multimodal analysis. Bristol: Channel View Publications.

Green, K. (2015). Deixis and the poetic persona, 1(2), 121-134.

Hanks, W. F. (2009). Fieldwork on deixis. Journal of Pragmatics, 41(1), 10-24.

Harmer, J. (2007). The practice of English language teaching (4th ed.). Harlow, UK: Pearson Longman.

Holder, D. E., \& Young, J. (2010). HEARD AND SEEN - Instructor Led Video and its Effect on Learning. Proceedings of the 2nd International Conference on Computer Supported Education, 186-189.

Holsti, Ole R. (1969). Content Analysis for the Social Science and Humanities. Reading, Massachusetts : Addison-Westley Publishing.

Kendon, A. (2004). Gesture: Visible Action as Utterance. Cambridge: Cambridge University Press.

Kress, G. (2003). Literacy in The New Media Age. London: Routledge.

Kusmiatun, A. (2016). Mengenal BIPA dan Pembelajarannya. Yogyakarta: K Media.

Lei, J. (2016). Advantages of Integration of Multimedia Network and Interactive English Teaching. ISME 2016 - Information Science and Management Engineering IV, (Isme), 107-110. https://doi.org/10.5220/0006444801070110

Levinson, S. (1983). Pragmatics. Cambridge: Cambridge University Press.

Mahsun. (2007). Metodologi Penelitian Bahasa: Tahap Strategi, Metode dan Tekniknya. Jakarta: Raja Grafindo Persada.

Media, K. C. (2016), June 14). Poster Film "3 Srikandi" Resmi Dirilis. Retrieved from https://entertainment.kompas.com/read/2016/0 6/14/204227510/poster.film.3.srikandi.resmi.di $\underline{\text { rilis }}$

Mulderrig, J. (2012). The hegemony of inclusion: A corpus-based critical discourse analysis of deixis in education policy. Discourse and Society, 23(6), 701-728.

Nohara, S., \& Brotoseno, I. (2016, August 04). 3 Srikandi. Diambil dari http://filmindonesia.or.id/movie/title/lf-300916-515790_3srikandi/award\#.W1APL5MxXIU

O'Keefe A, Clancy, B and Adolphs, S. (2011). Introducing Pragmatics in Use. London: Routledge.

Parker, F. M., \& Faulk, D. (2004). Lights, camera, action: using feature films to stimulate emancipatory learning in the RN to BSN student. Nurse Educator, 29(4), 144-146.

Prasch, A. M. (2016). Toward a rhetorical theory of deixis. Quarterly Journal of Speech, 102(2), 166-193.

Putrayasa, I.B. (2014). Pragmatik. Yogyakarta: Graha Ilmu.

Rahmawati, N. S., Santoso, A., \& Andajani, K. (2017). Respons Siswa Kelas Vii Terhadap. Respons Siswa Kelas VII Terhadap Pembelajaran Teks Laporan Hasil Observasi Dengan Media Video Pengetahuan, 2(1), 1092-1096.

Richards, J. C., \& Rodgers, T. S. (2001). Approaches and Methods in Language Teaching. Cambridge: Cambridge University Press.

Sugiyono. (2017). Metode Penelitian Kuantitatif, Kualitatif, dan R\&D. Bandung: Alfabeta.

Tanskanen, S. K. (2006). Collaborating towards coherence: Lexical cohesion in English discourse. Amsterdam, Netherlands: John Benjamins. 